\title{
Balancing Fun and Learning through a User Interface: A Case Study of Wii Game
}

\author{
Si Jung Kim ${ }^{1}$, Kichol Lee ${ }^{1}$ and Yeonjeong Park ${ }^{3^{*}}$ \\ ${ }^{1}$ University of Nevada, Las Vegas, USA \\ [e-mail: sj.kim@unlv.edu] \\ ${ }^{2}$ Virginia Tech, Blacksburg, USA \\ [e-mail: kichol@vt.edu] \\ ${ }^{3}$ Honam University, Gwangju, South Korea \\ [e-mail: ypark@honam.ac.kr] \\ *Corresponding author: Yeonjeong Park
}

Received Septebmer 20, 2018; revised November 11, 2018; accepted December 9, 2018; published July 31, 2019

\begin{abstract}
Designing a user interface is important because the user interface determines the level of physical and mental engagement of the user resulting in their level of learning. This paper investigated how physical engagement through a different user interfaces is associated with fun and learning and presented a theoretical physical engagement model called, PEM, developed based on an empirical user study. The PEM model describes how a game user interface is associated with the level of fun and learning, particularly in playing a full body engaged game. There are many different types of games but the Wii Tennis, an embodied interactive game, was chosen as an instance of full body engaged game. A user study with 32 participant's age ranged from 21 to 40 years old revealed that there is a positive correlation between both fun and learning and the level of physical engagement through two different user interfaces. The results of the study showed that the extent of fun and learning are associated with the physical engagement of the player through an interface. As an implication from the study, the result recommend that the level of user engagement is realized by an effective user interface, and the level of physical engagement is determined by the level of authenticity bridged by the user interface.
\end{abstract}

Keywords: Learning, Engagement, Interface, Game, Fun, Embodied 


\section{Introduction}

Games offer players fun, challenge, motivation and even thrills. Researchers and educators have attempted to find a role not only for entertainment, but also for educational potentials such as strategic thinking, problem solving, analytic skills, and collaboration[1-5]. However, the question that still remains would be investigating how the game interface with physical constraints affects the level of players' fun and learning. For instance, the Wii Tennis game, an embodied interactive game, is known as a successful case of providing the player with fun and an opportunity that increases players' physical activity, compared to similar conventional exertion games. However, playing the Wii Tennis lacks in providing an identical or even similar learning environment in which a real tennis racket would provide the player with several affordances such as weight, size and shape, and thus affects the physical engagement of the player that would result in different levels of learning. This led to two main purposes of this research. The first of them was to explore whether the relationships in which physical engagement of the player, accomplished through a user interface, affects fun and learning. The second was to establish a theoretical model about how physical engagement is associated with fun and learning called, the physical engagement model (PEM).

This paper is presented in five sections, including the introduction. The background section describes a literature review about game-based learningand its conceptual framework. The research method section describes a quasi-experimental design that includes participant criteria, tasks procedures and data analysis followed by results and discussions. The paper concludes with the conclusion section that summarizes the study and possible extensions of this study.

\section{Literature Review}

A game can be defined as an environment in which a player is willing to follow rules and face adventures. Garris, Ahlers, and Driskell [6] defined a game as "an activity that is voluntary and enjoyable, separate from the real world, uncertain, unproductive in that the activity does not produce any goods of external value, and governed by rules” (p. 442). Carroll [7] noted that players have fun when their emotions are attracted or captured during game play. Malone summarized three factors of fun - challenge, fantasy, and curiosity $[8,9]$. While challenge in a game provides players with difficult, uncertain goals to achieve, fantasy evokes mental images of physical objects or social situations which are not actually present. Through fantasies, players can satisfy their needs or desires which cannot occur in their real life. Lastly, curiosity motivates players to achieve the given goals and fantasy-fulfilments. All of these factors of a game effectively contribute to the high engagement and motivation of players.

In addition to the aforementioned emotional and affective values of games, cognitive values have also been recognized by several scholars. Greenfield [2] indicated that playing computer games can facilitate the development of particular analytic skills. Salomon [5] also highlighted that there is a "cognitive residue" (p. 34) caused by interaction with the requirements of a computer game. Currently, the combination of virtual reality technologies and communication tools has added several more important affordances such as immersive environment, social interaction and collaboration. Some computer and video games, as stated by Squire[10], have great potential. These potentials are: (1) eliciting powerful emotional reactions (e.g., fear, power, aggression, wonder, and joy), (2) incorporating interesting design elements (e.g., character traits, game rewards, obstacles, narrative, competition, and collaborative 
opportunities), and (3) creating a dynamic socio-cultural context which brings friends and family together.

\subsection{Game-based Learning}

There have been two approaches in regard to game-based learning: (1) using commercially successful games for educational purposes and (2) making educational games more interesting and appealing. Regardless which approaches are taken, as was noted by Prensky [11], game-based learning "alter[s] the learning process in a way that appeals to, and excites, people from the game generations” (p.18). As today's learners become more technologically savvy and accustomed to sophisticated digital media, several researchers and educators have argued that our learning environment should also evolve to allow learners to become more engaged and interactive in a social and constructive manner, rather than pursuing traditional content-centred approaches [12, 13]. Game-based learning is an effective way to meet this trend and need, because such games afford unique values to both learners and instructional designers.

\subsection{Learning with the Wii Game}

Prior research has been conducted with Wii games in many areas. Researchers have found the physical engagement of Wii games to be higher than that of traditional video games [14-16]. The possible use of Wii as a tool for rehabilitation has also been investigated [16-21]. Deutsch et al. [17] reported improved rehabilitation of a person with cerebral palsy. Goldberg et al. [18] reported possible improvements in the rehabilitation of patients with acquired brain injury, indicating improvements in hand-eye coordination, social participation and reduced feelings of helplessness. Spencer et al. [20] showed application of Wii games for rehabilitation efforts, particularly of the wrist and forearm. Many other researchers also studied how the Wii system can be used in learning [15, 22-23]. For instance, Dede [15] investigated how immersion is related to learning, while Huang et al [22] studied the effects of a 3D virtual environment on both students and instructors.

Recently, the exercise games Wii Sports and Wii Fit were examined by researchers [24]. Wii Sports is a virtual athletic game consisting of several exertion games, released by Nintendo. The unique feature of this game stems from the concept of the embodied interaction that a part of human body plays in shaping the mind $[25,26]$. Another distinguishing feature of Wii Tennis is that the game is played with the Wii remote controller, allowing the user to interact with the game in 3D. It is the primary interface in the game and senses user motions to allow the user to control the virtual tennis ball based on physical actions, enabling the hitting of the ball and swinging of the racket with similar motions. It enables the input of user behaviors such as swinging by detecting acceleration and orientation of the controller in three dimensions [27]. However, the user may not be fully engaged in the game, because he or she would feel that the virtual ball contact point is in their hand. To overcome the limitation and increase the engagement, a Wii skin for tennis was designed. The Wii skin for tennis could help players to create more natural postures, as it places the virtual ball contact point somewhere in the center of the Wii skin. This may result in a more engaging experience; however, the Wii tennis skin still has problems since the player would feel as if he or she were hitting the ball with a hand rather than a racket. 


\subsection{Factors of Game-based Learning}

Game-based learning is associated with four components: fun, motivation/challenge, physical engagement, and user interface. Fig. 1 shows the four components and their relationships identified from the above literature review. As shown in the figure, the four components are inter-related with each other, and a user interface plays a crucial role for determining the level of physical engagement that are connected to fun and motivation and challenge that is associated with the level of learning. A user interface is defined as the aggregate of methods dealing with information by which users interact with particular systems such as machines, devices, and programs (28). As seen in Fig. 1, it provides a means of either input, allowing users to manipulate a system, or output, allowing a system to produce the effects of the user's manipulation. As Van Eck [29] stated, a good game constantly requires input from the learner and provides learners with feedback through the user interface.

Learning refers to the truthfulness of an object, attributions, sincerity, and intentions. It is one of the core elements which can induce better engagement in learning, cognitively or physically [30]. There are many factors that affect the authenticity of a task, such as context, learner motivation, feedback, social interaction, and social presence. Authenticity lies not in the learner, the task or the environment, but in the dynamic interactions among these various components [4]. Motivation and challenge are closely related to instructional contents. For example, some aspects utilized in good games to make them fun are also applied in the design of instructional events in several steps such as gaining attention, stimulating recall of prior learning, informing learners of the objective, presenting the stimulus, eliciting performance, and providing feedback [31].

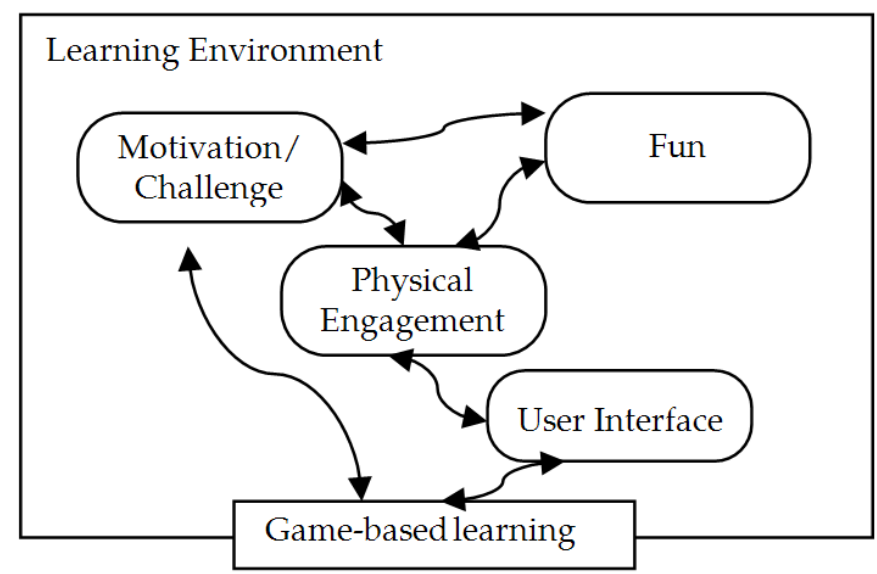

Fig. 1. A conceptual model of a physical engagement model from the literature review

As Lazzaro [32] found that having fun is an important factor in game-based learning because it is the major reason that people enjoy playing a game. He related having fun with emotion, and explained that "people play games to change or structure their internal experiences" (p.7). XEO design, where she is president, demonstrated 4Keys2Fun, which explains that four keys to emotion are the reasons why people play games, and each key shows different aspects of the experience of the players. The four keys include the following: (1) hard fun - supporting Fiero (an Italian word for personal triumph) as they master difficult steps and feel goal-achievement; (2) easy fun - supporting curiosity as they experience new worlds in games and simply enjoy fantasies; (3) serious fun - supporting excitement as they find 
meaning and value and apply their feeling and behaviors in the real world; and (4) people fun - supporting amusement as they get together with friends through the game and build social bonds and team work.

Engagement is the act of sharing in activities and the degree or depth of interaction[33, 34], and includes both mental and physical engagement. Physical engagement represents tying part of or the entire human body to an interaction and can be realized through authenticity of an object. Engagement theory began early in the 1980's, with the fundamental idea that learners should engage in activities through interaction with others during learning. In the engagement process, technology can facilitate engagement of the learner and/or teacher. It can also be utilized to help both the learner and teacher by providing interactive environments in which they can interact. During this process, an interface plays a bridge role among the learner, teacher and environment.

\section{Research Method}

\subsection{Research Questions}

An empirical research design was developed to investigate how a user interfaces is associated with fun and learning. An one factors within subject design has been designed to examine the players' level of fun and learning that would be influenced by the different user interfaces, the Wii remote and a tennis real racket. The specific research questions were:

(1) Could the player have more fun and learn better if the game interface were more physically engaged to the player?

(2) Can the player feel the ball contact point out of his or her hand if the Wii remote were attached to the center of the tennis racket head?

(3) Can interfaces having different physical engagement factors affect or change the quality of experience in a user?

\subsection{Experiment Setting}

A quasi-experimental design as one factor within subject design was employed for to address the research questions above. A total of 32 adult players participated in this experiment. The Wii tennis game was chosen as an embodied game and was utilized in a room with a projector hanging on the ceiling with a big screen. As the most important instrument, user interfaces of two different levels were prepared: (1) the Wii remote and (2) a real tennis racket, where the Wii remote was attached on the middle of the racket head. The data matrix of this design is represented in Table 1. The letter " $\mathrm{S}$ " in the table denotes the participants, and the number "32" represents the total number of participants.

Table 1. One factor within subject design data matrix

\begin{tabular}{|c|c|c|}
\hline & \multicolumn{2}{|c|}{ Type of Interface } \\
\hline & The Wii remote & A real tennis racket \\
\hline Trial 1 & S1.... S32 & S1....S32 \\
\hline Trial 2 & S1... S32 & S1...S S32 \\
\hline
\end{tabular}




\subsection{User Interface and Tasks}

Two different user interfaces were prepared. One was the Wii remote, as shown in Fig. 2(a), and the other was a real tennis racket in which a Wii remote attached to the centre of the tennis racket head, as shown in Fig. 2(b). The two interfaces were expected to provide the player with different levels of physical engagement while playing Wii Tennis. An additional real tennis racket with a different grip size was prepared to accommodate participants with smaller hands, as shown in Fig. 2(c). The participants played the game twice with the Wii remote and twice with the real tennis racket, as shown in Fig. 2(d), and Fig. 2(e).

The presentation order of the two game interfaces was counter-balanced to prohibit learning effects. Odd numbered participants started the game with the Wii remote first, while even numbered participants started the game with the real tennis racket first. Use of a room with a projector hanging on the ceiling was selected so that the projector would not hinder the movement of participants.

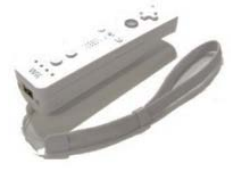

(a)

The Wii remote

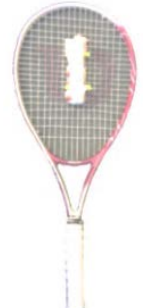

(b)

A real tennis racket with the Wii remote embedded in the head (for male participants)

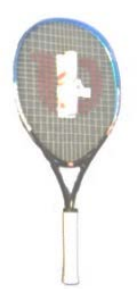

(c)

Another real tennis Playing the game with the Playing the game with a real racket with a Wii remote tennis racket. different grip size

(for female participants) (d)

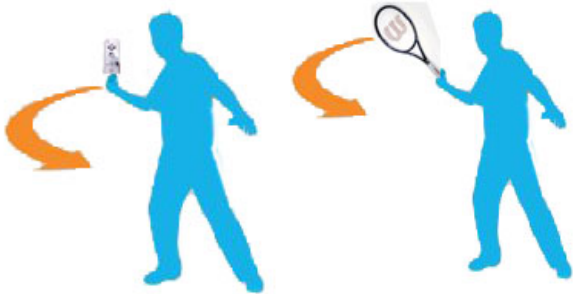

(e)

Fig. 2. Two types of game interfaces and user tasks

\subsection{Data Collection and Analysis}

Data collection proceeded in five steps: pre- questionnaire, training of participants, observation, post-questionnaire, and expert review. A pre-questionnaire was used as a first step to gather demographic information. Once the participants completed the pre-questionnaire, they had a familiarization session about how to use the Wii remote and play Wii Tennis. They then participated by playing Wii Tennis, once with the Wii remote and another time with the real tennis racket, alternatively. After the games with the two user interfaces, the participants took a post-questionnaire and rated their levels of engagement and fun for both interfaces.

Data analysis was performed in mixed methods by conducting quantitative and qualitative analysis. The quantitative analysis phase was employed to analyze the different perceptions of participants in regard to their demographic characteristics (gender and age), prior experiences with Wii games, prior experiences playing tennis, and the two different user interfaces (Wii Remote Vs. Tennis Racket) through descriptive statistics. Correlation analysis was also conducted to verify the relations among variables. Since only a small number of participants was incorporated, the study had limitations in the verification of statistical meaningfulness. For the in-depth analysis, qualitative analysis was conducted simultaneously. Observation and video-recording substantially helped to discover the different participant's postures and movement patterns. Furthermore, an expert in tennis was invited to evaluate how participants' behaviors were different as they used the different interfaces. Major variables, data collection, and data analysis are summarized in Table 2. 
Table 2. Research variables, data collection, and analysis methods

\begin{tabular}{|c|c|c|c|}
\hline \multicolumn{2}{|r|}{ Variables } & Data Collection & \multirow{4}{*}{$\begin{array}{l}\text { Data Analysis } \\
\text { [Quantitative] } \\
\text { - Descriptive } \\
\text { Statistics } \\
\text { - Correlation Analysis }\end{array}$} \\
\hline \multirow{4}{*}{$\begin{array}{l}\text { Independent } \\
\text { Variables }\end{array}$} & Gender and Age & \multirow[t]{3}{*}{ Pre-questionnaire } & \\
\hline & Prior Experiences of Wii Game & & \\
\hline & $\begin{array}{l}\text { Prior Experiences of Tennis } \\
\text { Game }\end{array}$ & & \\
\hline & $\begin{array}{l}\text { User Interface } \\
\text { (Wii Remote vs. Tennis Racket) }\end{array}$ & Video Recording & \multirow{6}{*}{$\begin{array}{l}\text { [Qualitative] } \\
\text { - Postures and } \\
\text { Movement Pattern } \\
\text { Observation } \\
\text { - Expert Review }\end{array}$} \\
\hline \multirow{5}{*}{$\begin{array}{l}\text { Dependent } \\
\text { variables }\end{array}$} & Convenience & \multirow{5}{*}{$\begin{array}{l}\text { Post-questionnair } \\
\text { e }\end{array}$} & \\
\hline & Interest, Fun & & \\
\hline & (Physical) Engagement & & \\
\hline & Easiness to Win and to play & & \\
\hline & Increased Physical Activity & & \\
\hline
\end{tabular}

\section{Results and Discussion}

\subsection{Participant Characteristics}

The criteria for participation were to be over 18 years old, male or female, and wanting to learn how to play tennis. A total of 32 participants, consisting of 16 males and 16 females, participated in the study. Their ages ranged from 21 to 40 years old. About $75 \%$ (24 out of the 32 participants) were experienced with Wii games, and 94\% (30 out of the 32 participants) were experienced with real tennis. Approximately 69\% (22 out of the 32 participants) were experienced both with the Wii game and real tennis. While none of the participants played tennis regularly, several participants were quite experienced tennis players.

In the case of the Wii game, none of the participants played regularly. In addition, no one claimed to be an expert Wii player. For the participants with experience in either the Wii game or tennis, they were asked to rate their skills. The results revealed that the male participants scored higher than the female participants, although the gap was not large.

\subsection{Interface Convenience and Interest in Game}

For the question about which game interface was more convenient between the Wii remote or the real tennis racket, about 94\% (30 out of the 32 participants) answered that playing Wii Tennis with the Wii remote controller was more convenient. On the other hand, about 69\% (22 out of the 32 participants) indicated that playing with the real tennis racket was more interesting than playing with the Wii remote. This result was the opposite of what we had expected. That is, if the game interface was more convenient to use, it was expected to enhance physical engagement of the player in motion and make the player more interested in the game. However, the participants had more fun with the real tennis racket even though it was not as convenient as the Wii remote. The low correlation between convenience and interests $(r=0.74$, $\mathrm{p}>.05$ ) showed that the convenience of the game interface did not affect interest in the game.

\subsection{Physical Engagement and Fun}

The participants were asked to select the game interface that made them more engaged in the game. About 69\% (22 out of the 32 participants) answered that the real tennis racket was made them engaged in the game more as the result is visualized in Fig. 3. Among them, about $91 \%$ (20 out of the 22 participants) answered that they had more fun with the real tennis racket than with the Wii remote when playing the game. 


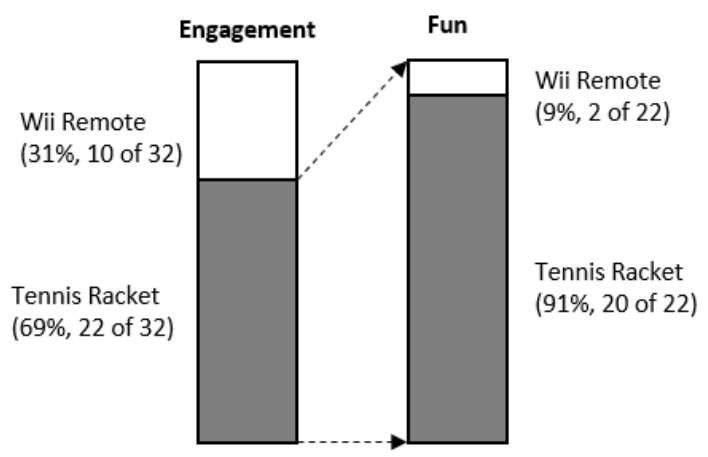

Fig. 3. The distribution of engagement and fun experienced when engaged in the case of using the Tennis Racket

In contrast, only $31 \%$ (10 out of the 32 participants) answered they were engaged more when playing with the Wii remote, as shown in Fig. 4.

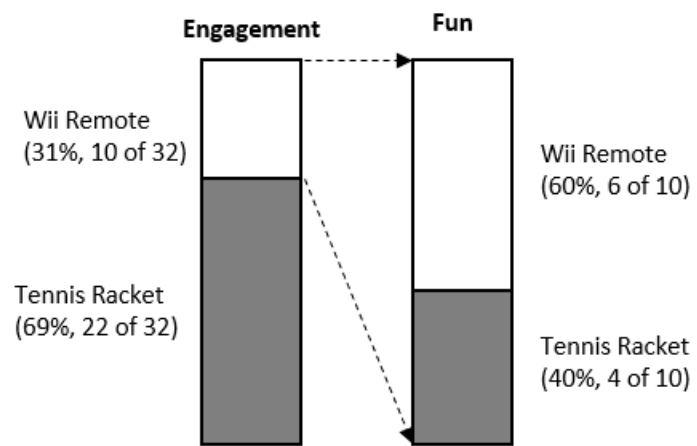

Fig. 4. The distribution of engagement and fun when engaged in the case of using the Wii Remote

Of these, $60 \%$ (6 out of the 10 participants) answered that the Wii remote was more fun than the real tennis racket. Regardless what an interface made them engaged in the game, the one engaged them gave more fun. However, participants engaged with the real tennis racket felt more fun than the other participants with the Wii remote shown in Fig. 3 and Fig. 4.

Fig. 5 below shows a mosaic plot examining the relationship between engagement and fun. A correlation analysis revealed that engagement and fun to have positive relations $(r=0.545$, $p<.05$ ). As seen in the figure, the majority of participants were engaged and had fun with the real tennis racket $(75 \%, 24$ out of the 32 participants), but only $25 \%$ (8 out of the 32 participants) were engaged with the Wii remote and had fun. This result showed that the game interface was closely associated with the level of engagement in the game as well as the interface influenced the level of fun while playing. 


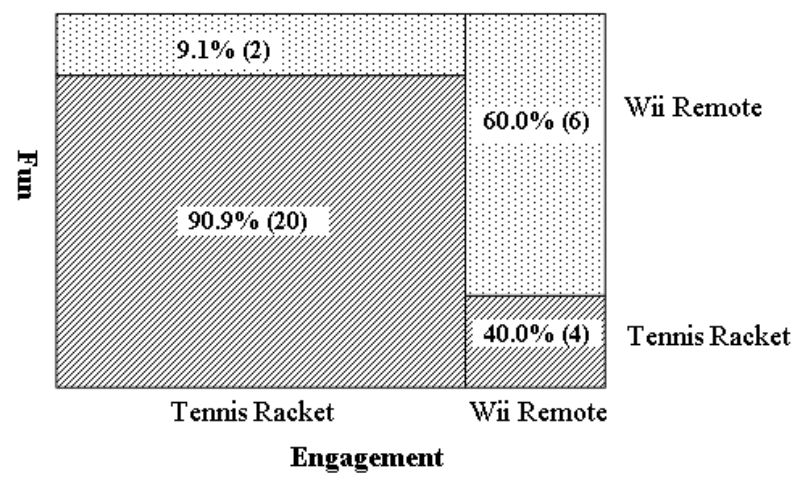

Fig. 5. A mosaic plot based on contingency analysis of fun by engagement postures and movement patterns

Observation found that Some participants commented that they began to sweat a little bit with the real tennis racket than the Wii remore and began gasping. From the comment, the game with the tennis racket provided more exercise than with the Wii remote. In addition to this, the post- questionnaire responses disclosed that the reasons for having fun were swinging (61\%, 20 out of the 32 participants), weight (26\%, 26 out of the 32 participants), and others (13\%, 13 out of the 32 participants) when using the real tennis racket.

\subsection{Physical Activity and Behaviors}

While the participants were playing the game, their behaviours were observed and analysed. All participants spent time to acquire knowledge of how to use the Wii remote and the real tennis racket before playing the Wii tennis game. Some of the participants asked the researcher why the Wii remote was attached to the centre of a tennis racket head. It seemed that they would like to know the purpose of the device to utilize it in the game. For example, they asked "Are we really going to play real tennis here?" when they saw the real tennis racket before starting the game, and said to themselves, "Wow, I'm playing tennis here," while they were playing with the real tennis racket. It seemed that they were enjoying the game and having fun with the real tennis racket by learning how to use it in the game. This was proven by the answer from all 32 participants that they felt more "increased physical activity" with the real tennis racket than the Wii remote.

We observed that the participants' physical behaviours changed when they switched between the two user interfaces. When using the Wii remote, they initially tried to hit the ball by forming postures and motions as in real tennis, but the participants used only their arms to hit the ball after playing the game for a little while, as captured in Fig. 6 (a) and (c). They did not make a full swing like in real tennis in order to hit the ball as they did in the beginning of the game. On the other hand, when they played Wii Tennis with the real tennis racket, they kept their postures as they would in real tennis, as captured in Fig. 6 (b) and (d). This indicated that the participants adapted themselves to the user interfaces based on the constraints and affordances of the user interfaces.

There were several learning and adaptation processes of the two interfaces during the game. Most participants spent time to adjust their body to the interfaces. Less time was spent for the Wii remote and more was spent for the real tennis racket, since playing with the real tennis racket was a bit more difficult due to its weight. The participants had to change and form 
postures according to the constraints of the real tennis rackets, such as weight and shape. For example, with the tennis racket, most participants used most of their bodies. Compared to the Wii remote, they created wider motions with the tennis racket and were more active in their play. They made active postures like in a real tennis game before and after contacting a ball as well as hitting a ball. It seemed that the racket made them form the appropriate posture because of its characteristics, such as weight, size and shape. As a result, the tennis racket enabled the participants to learn tennis in terms of a physical learning process.

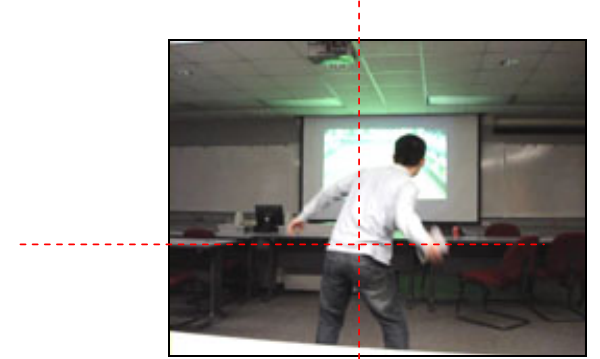

(a) Initial posture with the Wii remote

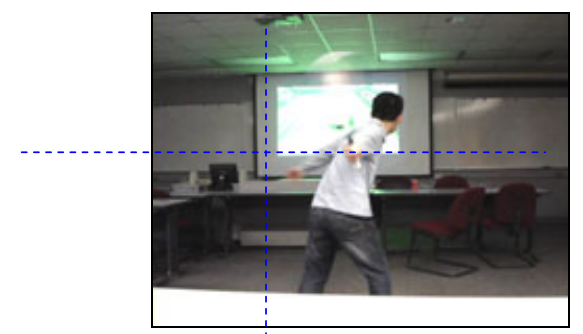

(b) Initial postuire with the real tennis racket

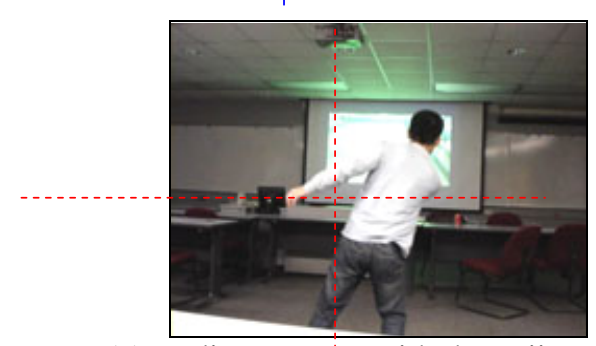

(c) Ending posture with the Wii remote

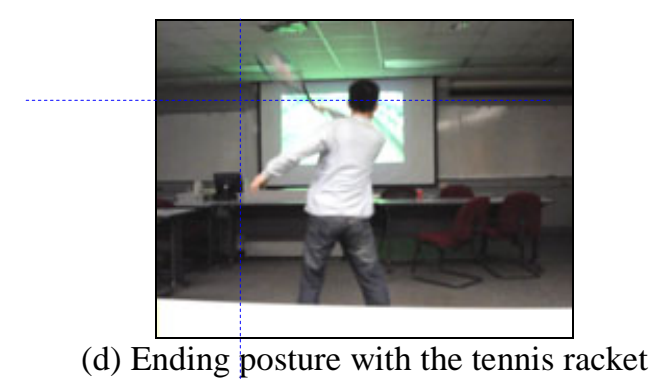

A participant with the Wii remote controller in Fig. 6 (a) gets his posture ready to hit the virtual ball. The posture is not fully developed compared to the posture formed with the real tennis racket shown in Fig. 6 (b).

A participant with the real tennis racket Fig. 6 (b) gets his posture ready to hit the virtual ball, and it is fully developed compared to the posture formed with the Wii remote shown in Fig. 6 (a).

A participant with the Wii remote controller in Fig. 6 (c) hit a ball and made an ending posture, but it was not fully developed as compared to the finish posture made with the real tennis racket shown in Fig. 6 (d).

A participant with the real tennis racket in Fig. 6 (d) made a fully developed posture after hitting the virtual ball. It is a full follow-up swing, like in real tennis.

Fig. 6. Participants' physical behaviours when using the two user interfaces 


\subsection{Expert Review}

In order to validate the findings described in the previous sections, an expert in tennis was invited to review the video recordings of the participants. Before showing the video to the expert, he was asked what skills and knowledge are necessary for a tennis player when learning tennis. The expert listed the five review criteria: swing form (mainly smoothness and good follow-through), flexibility, core muscle and muscle strength, hand-eye coordination and weight transfer. We then asked the expert to analyse the videos based on the three criteria: learning effectiveness in comparing the two interfaces (the Wii remote and tennis racket), differences in particular patterns and motions, and other considerations in the aspect of the educational purpose of the Wii game.

When asked whether the learning effects were found when using the Wii remote, the expert answered as follows:

The Wii remote detected swing speed and the players learn that right away. When they tried to hit harder, they started using wrist flicks or abbreviated their swing to increase their swing speed, which can lead to poor tennis swing and can also cause injuries. Also, due to the light swing-weight of the Wii remote compared to the tennis racquet, the players will not learn how a tennis racquet feels during the swing.

He also pointed out the negative effects of playing the Wii game with the remote, which resulted in a poor tennis swing. On the other hand, he answered that the tennis racket seemed a bit better. The swing weight was higher, so they tried to utilize their core muscles more. However, in terms of developing a good swing form, it was still impractical mainly because the feel of the ball impact on the racquet and the necessary swing lead time to the ball contact were not skills that can be learned from the game.

In regard to the particular patterns and motions when the players played with the Wii remote, the expert reviewed that:

A player with the Wii remote used mainly the wrist and arm, while a player with the real tennis racket tried to utilize his tennis swing in the beginning. The player started to abbreviate his follow through, so playing actually started to deteriorate his skills. The player with the Wii remote's swing seemed less jerky, probably due to the swing-weight of the racquet. ...A player with the real tennis racket used his full swing with no abbreviations, while a player with the Wii remote showed the same trends as with remote-only playing. The player with the real tennis racket played longer.

Lastly, we inquired if there were other possibilities and considerations for using the Wii game as a training method for real tennis playing. The expert answered as follows:

The Wii game could be of help to beginners as to teach them the need for smooth swing due to the swing-weight. However, as far as the real necessary skill set needed for tennis is concerned, the Wii game would not be helpful for intermediate or advanced learners. Also, most people will just use the remote, so unless that racquet-remote setup is present, it will not be an effective learning tool for tennis. 


\subsection{Engagement Functions}

The results of this study showed that the extent of fun and learning are associated with the physical engagement of the player through an interface. There was a positive correlation that better physical engagement through a user interface would create more fun, as described in equation 1.

$$
\text { fun } \propto f \text { (engagement of humanbody) }
$$

Equation 1 represents that the fun of a game is a function of the engagement of the human body, linked by the user interface. The human body is both a modulator and a measure of the quality of engagement in embodied interactive games. According to equation 1, better physical engagement will be realized by considering affordance factors such as size, weight and shape in designing game interfaces. In the experiment, the level of fun in the game was a function of engagement by way of the affordance of a real tennis racket. The different affordances of the user interfaces affected the physical engagement of the users, as represented in equation 2.

$$
\text { engagement } \propto f \text { (affordance of user int erface) }
$$

Equation 2 implies that affordance, including constraints such as shape, weight and size of a game interface, affects the level of physical engagement in the game, and is also associated with the level of physical activity. An additional finding was that all participants answered that the game with the real tennis racket increased their physical activity because of its weight and shape while swinging.

\subsection{Physical Engagement Model (PEM)}

A theoretical physical engagement model called, PEM was developed as the experiment was conducted and the data were reviewed, as shown in Fig. 7. The PEM represents the relationships amongst physical engagement, fun, and learning. It also illustrates values in both the entertainment aspect (the fun part) and educational aspect (the learning part). The values consist of emotional and cognitive elements in the broad sense. In regard to emotional values, the fun was explained by "challenging, curiosity, and fantasy". These sub constructs explain why people play a game. As Lazzaro [28] highlighted, game players feel goal-achievement (hard fun), fulfil curiosity (easy fun), find meaning and values(serious fun), and enjoy being together in case of collaborative game (people fun). On the other hand, the aspect of cognitive values explains that game players are naturally able to understand the rule of game, recognize the patterns, practice some specific posture, and adapt the new skills.

In the PEM model, the embodied interaction promotes players' physical activity, and the user interface plays the important role of bridging physical engagement and mental engagement as an authentic tool. Specifically, physical engagement plays the role of associating fun and learning, increasing both the fun (emotional value) and learning (cognitive value). There is a positive correlation that when a player is more engaged in the game, he or she has more fun and learns more effectively. The balance between fun and learning needs to be adjusted by controlling physical engagement through an interface.

With regards to mental engagement, playing the Wii game would not be limited to teaching a sort of motor skills that was intended by the developers of this particular game. Through playing the game, as Salomon [5] indicated, cognitive values will remain in players' 
minds. For example, in tennis or ping pong, adaptation for the ball, posture formation, patterns of success or failure, and rules of games are formed through player drills and practice. From our observation, when participants played the game either with the Wii remote or the real tennis racket, the cognitive learning process was activated to gain knowledge of how to use the two interfaces to utilize them in the game.

As another important dimension, the physical engagement at the centre of Fig. $\mathbf{7}$ is a driver to promote the fun and learning of players. Without full engagement, players would not experience fun, and less learning would occur. The game interface in the model plays an important role because it influences the level of engagement of the players by keeping them in sync, especially in a dynamic game in which user inputs are based on the position and orientation of the user. It was discovered that the level of physical engagement is related to the formation of an appropriate posture and creating smooth motions.

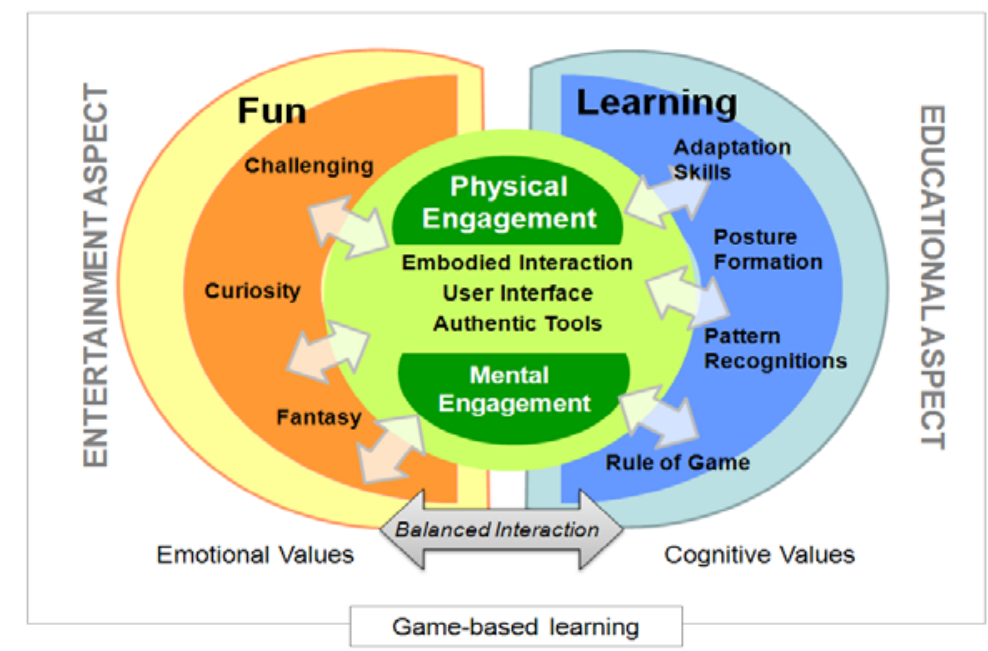

Fig. 7. A physical engagement model (PEM) in which fun and learning is enhanced and balanced through physical engagement.

\section{Conclusions and Future Works}

This paper presented how physical engagement through different user interfaces is associated with fun and learning. The paper presented the physical engagement model (PEM) which represents the relationships between fun, and learning, where a user interface is a crucial factor determining the level of fun and learning. It is important to know that the level of user engagement is realized by an effective user interface, and the level of physical engagement is determined by the level of authenticity bridged by the user interface.

There were a few limitations in the study that would affect the study results. The first was the number of iterations of the play that the participants only took two iterations of the game. It was possible to observe how the participants interacted with the two interfaces during the two interactions, but it was not sufficient to observe any long term effects of the different interfaces. This could be important, since learning takes time and requires lots of repetitive practice. The second limitation was participant preferences about playing time and the place where they would like to play. The place and amount of time would result in different outcomes as certain participants provided comments on the experimental setting. For example, they worried that the real tennis racket might hit something while playing. This may have affected their performance. As another limitation, since the study focused only on simulated Wii Tennis as 
an embodied interaction game, there is a limitation to generalize the results of this study to other computer games or educational games on the whole, which attempt to use in-game elements to develop out-of-game knowledge, skills, and attitudes.

In spite of the several limitations, this study is still meaningful in that it demonstrated that increasing the authenticity of the physical component of an embodied virtual simulation for training purposes may help novices or beginners acquire key foundational skills, requiring fewer substantial interventions as trainees progress to higher levels of training. With the considerations of elements in the physical engagement model (PEM), this study highlighted that game designers need not only to focus on entertainment values such as the fun or interest, but also on cognitive values such as correct movements that might be useful in a real-world context, and the acquisition of knowledge or skills to use core muscles through authentic user interfaces.

A natural extension of this research is to apply the PEM model to other instructional tools and measure its effectiveness. An attempt to simulate other similar cases (golf games, driving games, etc.) has been planned to provide richer implications from the study. Also, an in-depth study with a real-world performance context will be investigated to provide practical suggestions necessary for the design of embodied games which fulfil a better balance among fun, learning and engagement.

\section{References}

[1] J. P. Gee, "What video games have to teach us about learning and literacy," Palgrave Macmillian, New York, 2007.

[2] P. M. Greenfield, "Mind and media: The effects of television, video games, and computers," Psychology Press, 2014. Article (CrossRef Link).

[3] E. Klopfer and S. Yoon, "Developing games and simulations for today and tomorrow's tech savvy youth,” Tech Trends, vol. 49, no. 3, pp. 33-41, 2005. Article (CrossRef Link).

[4] S. A. Barab, K. Squire, and B. Dueber, "A co-evolutionary model for supporting the emergence of authenticity,” Educ. Technol. Res. Dev., vol. 48, no. 2, pp. 37-62, 2000. Article (CrossRef Link).

[5] G. Salomon, "Cognitive effects with and of computer technology," Communication research, vol. 17, no. 1, pp. 26-44, 1990. Article (CrossRef Link).

[6] R. Garris, R. Ahlers, and J. E. Driskell, "Games, motivation, and learning: A research and practice model,” Simul. Gaming, vol. 33, no. 4, pp. 441-467, 2002. Article (CrossRef Link).

[7] J. M. Carroll, "Beyond fun," interactions, vol. 11, no. 5, pp. 38-40, 2004.

[8] T. W. Malone, "What makes things fun to learn? Heuristics for designing instructional computer games," in Proc. of presented at the Proceedings of the 3rd ACM SIGSMALL symposium and the first SIGPC symposium on Small systems, pp. 162-169, 1980. Article (CrossRef Link).

[9] T. W. Malone, "Heuristics for designing enjoyable user interfaces: Lessons from computer games," in Proc. of presented at the Proceedings of the 1982 conference on Human factors in computing systems, pp. 63-68, 1982. Article (CrossRef Link).

[10] K. Squire, "Video games in education," International Journal of Intelligent Games and Simulations, vol. 2, no. 1, pp. 957-962.

[11] M. Prensky, "Digital game-based learning," McGraw-Hill, New York, 2001.

[12] Y. J. An and C. J. Bonk, "Designing digital game-based learning environments," Tech Trends, vol. 53, no. 3, pp. 43-8, 2009.

[13] J. M. Brill and Y. Park, "Facilitating engaged learning in the interaction age taking a pedagogically-disciplined approach to innovation with emergent technologies,” Int. J. Teach. Learn. High. Educ., vol. 20, no. 1, pp. 70-78, 2008.

[14] J. Bloom, R. Hunker, K. McCombs, B. Raudenbush, and T. Wright, "Nintendo Wii vs. Microsoft Xbox: Differential effects on mood, physiology, snacking behavior, and caloric burn,” Appetite, vol. 51, no. 2, p. 354, 2008. Article (CrossRef Link). 
[15] C. Dede, “Immersive interfaces for engagement and learning,” science, vol. 323, no. 5910, pp. 66-69, 2009.

[16] D. J. Kerrigan, H. Chen, M. D. Wiederhold, L. Gamberini, and B. K. Wiederhold, "Evaluation of the Nintendo Wii for physical exercise and rehabilitation,” presented at the Cyberpsychology \& Behavior, vol. 12, pp. 107-107, 2009.

[17] J. E. Deutsch, M. Borbely, J. Filler, K. Huhn, and P. Guarrera-Bowlby, "Use of a low-cost, commercially available gaming console (Wii) for rehabilitation of an adolescent with cerebral palsy,” Phys. Ther., vol. 88, no. 10, pp. 1196-1207, 2008. Article (CrossRef Link).

[18] G. Goldberg, H. Rubinsky, E. Irvin, E. Linneman, J. Knapke, and M. Ryan, "Doing WiiHab: Experience With the Wii Video Game System in Acquired Brain Injury Rehabilitation0034,” Journal of Head Trauma Rehabilitation, vol. 23, no. 5, p. 350, 2008. Article (CrossRef Link).

[19] A. Ramchandani, K. Carroll, R. Buenaventura, J. Douglas, J. Liu, "Wii-habilitation increases participation in therapy,” 2008 Virtual Rehabilitation, p. 69, 2008.

[20] S. J. Spencer et al., "A low cost parallel robot and trajectory optimization method for wrist and forearm rehabilitation using the Wii,” pp. 869-874, 2008. Article (CrossRef Link).

[21] van den Hoogen WM Wouter, W. W. IJsselsteijn, and de Kort YAW Yvonne, "Yes Wii Can! Using digital games as a rehabilitation platform after stroke - The role of social support," in Proc. of Virtual Rehabilitation International Conference, pp. 195.

[22] K.-M. Huang, J.-H. Chen, C.-Y. Shen, L. R. Chao, and T. K. Shih, "Developing the 3D adventure game-based assessment system with Wii remote interaction,” in Proc. of presented at the International Conference on Web-Based Learning, pp. 192-195, 2009. Article (CrossRef Link).

[23] K. Peters, "Influence of Real-World Ten-Pin Bowling Experience on Performance during First-Time Nintendo,”.

[24] R. Brown, H. Sugarman, and A. Burstin, "Use of the nintendo wii fit for the treatment of balance problems in an elderly patient with stroke: A case report,” Int. J. Rehabil. Res., vol. 32, no. 1, pp. S109-S110a, 2009. Article (CrossRef Link).

[25] A. Clark, “An embodied cognitive science?,” Trends Cogn. Sci., vol. 3, no. 9, pp. 345-351, 1999. Article (CrossRef Link).

[26] P. Dourish, "Where the action is: the foundations of embodied interaction," MIT press, 2004.

[27] Sreeram Sreedharan, Edmund Zurita, Beryl Plimmer, and Proceedings of the 19th Australasian conference / Computer-Human Interaction : Entertaining User Interfaces (OZCHI '07), 3D input for 3D worlds. ACM, 2 Penn Plaza, Suite 701, New York, NY 10121-0701, USA, 2007.

[28] M. W. Lansdale and T.C. Ormerod, “Understanding Interface,” Academic Press, San Diego, 1994.

[29] R. Van Eck, "Digital game-based learning: It's not just the digital natives who are restless," Educ. Rev., vol. 41, no. 2, p. 16, 2006.

[30] B. Shen and A. Chen, "Examining the Interrelations among Knowledge, Interests, and Learning Strategies,” J. Teach. Phys. Educ. J. Teach. Phys. Educ., vol. 25, no. 2, pp. 182-199, 2006. Article (CrossRef Link).

[31] R. M. Gagne, “The conditions of learning,” 1970.

[32] N. Lazzaro, “Why We Play Games:Four Keys to More Emotion Without Story,” XEODesign, ${ }^{\circledR}$ Inc.

[33] Anne Rose, Ben Shneiderman, Catherine Plaisant, and practices Proceedings of the 1st conference / Designing interactive systems: processes methods, \&. techniques (DIS '95), An applied ethnographic method for redesigning user interfaces. ACM, 2 Penn Plaza, Suite 701, New York, NY 10121-0701, USA, 1995.

[34] B. Shneiderman, "Designing the user interface: strategies for effective human-computer interaction,” Boston: Pearson, 2018. 


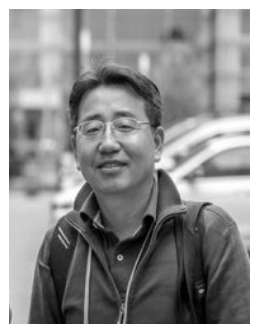

Si Jung “SJ" Kim is an Assistant Professor in the Howard R. Hughes College of Engineering and College of Fine Arts at the University of Nevada, Las Vegas (UNLV). SJ received his PhD in Human Factors and HCI from Virginia Tech. His research interests lie in the area of interactive media sciences and his current focus is in the use of augmented virtual reality as assessment tools and learning objects.

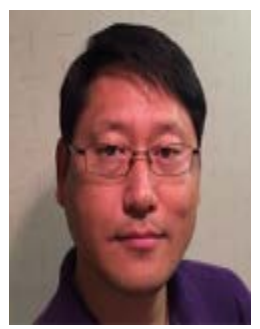

Kichol Lee is a research assistant professor of Industrial and Systems Engineering at Virginia Tech. He received a Ph.D. in Human Factors Engineering at Virginia Tech in 2011. As a manager of Auditory Systems Lab at Virginia Tech, he conducts various projects related to product design and human audition. In recent years, he conducted several human auditory situation awareness projects. He also is chief scientist of HEAR, LLC, a design, testing, and litigation support company.

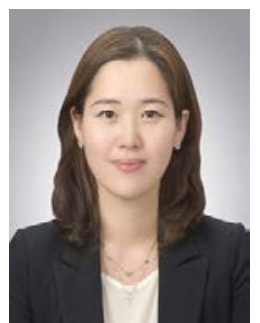

Yeonjeong Park is an assistant professor at the Honam University, South Korea. She received her Ph.D. in Instructional Design and Technology at Virginia Tech. Her research interests focus on social theories of learning, educational data mining, learning analytics and emerging technologies in education and training. 